\title{
WISATA HUTAN DI DESA DAYAK KANAYATN
}

\author{
Canggita Lusya ${ }^{1)}$, Sutarki Sutisna ${ }^{2)}$ \\ ${ }^{1)}$ Program Studi S1 Arsitektur, Fakultas Teknik, Universitas Tarumanagara, \\ canggitalusyazhang@gmail.com \\ 2) Program Studi S1 Arsitektur, Fakultas Teknik, Universitas Tarumanagara, sutarkis@gmail.com
}

Masuk: 04-07-2021, revisi: 14-08-2021, diterima untuk diterbitkan: 23-10-2021

\begin{abstract}
Abstrak
Deforestasi sudah tidak asing lagi didengar oleh masyarakat di Kalimantan Barat, bahkan sering menjadi pusat perhatian nasional dan dunia, salah satunya wilayah Kabupaten Kuburaya Kecamatan Sungai Ambawang. Dikarenakan fungsi daerahnya sebagai kawasan yang memproduksi hasil hutan. Kehidupan masyarakat lokal masih sangat bergantung pada hutan, dimana masyarakat dayak memiliki persepsi holistik terhadap hutan. Bagi mereka, hutan tidak hanya bermakna ekonomi melainkan juga sosio budaya dan religious. Tingkat deforestasi hutan yang sangat tinggi menyebabkan alam dan budaya pada masyarakat lokal mulai terpinggirkan akibat tidak mampunya budaya beradaptasi dengan perubahan kondisi kawasan (dengan hilangnya tutupan hutan / deforestasi), sehingga penelitian ini dilakukan penerapan pemberdayaan budaya yaitu, dengan memperkuat ekowisata budaya didaerah setempat dan menciptakan kehidupan masa lampau, yang dapat mengingatkan kembali budaya Dayak Kanayatn pada generasi muda di Desa Korek sangat diperlukan, melalui studi pendekatan tipologi Dayak Kanayatn, pantun syair lagu tarian jonggan dan pola pemukiman Desa Korek dan wisata hutan mengisahkan makna hutan rimba bagi masyarakat dayak yang bernilai sangat penting bagi kehidupan aktivitas sehari - hari mereka. Dijadikan sebagai desain dasar dalam membentuk zoning, pola sirkulasi, orientasi bangunan, dan bentuk bangunan. Desain proyek ini menggunakan metode kualitatif dengan studi kasus dan metode design milik Kengo Kuma. Hasil penelitian berupa desain ekowisata budaya Dayak Kanayatn dengan penerapan aspek beyond ecology, yang dapat meningkatkan keterlibatan masyarakat lokal dalam mengoptimalkan program kegiatan pelestarian SDA dan budaya.
\end{abstract}

Kata kunci: Budaya; Dayak Kanayatn; ekologi; hutan; wisata.

\begin{abstract}
Deforestation is no stranger to people in West Kalimantan and even often becomes the center of national and world attention, one of which is the Kuburaya Regency, Sungai Ambawang District. Due to the function of the area as an area that produces forest products. The lives of local people are still very dependent on the forest, where the Dayak community has a holistic perception of the forest. For them, the forest does not only mean economic but also socio-cultural and religious. The very high rate of forest deforestation causes nature and culture in local communities to be marginalized due to the inability of culture to adapt to changes in regional conditions (with loss of forest cover/deforestation), so this research was carried out by applying cultural empowerment, namely, by strengthening cultural ecotourism in the local area and creating Past life, which can remind the Kanayatn Dayak culture to the younger generation in Korek Village, is very necessary, through a study of the Kanayatn Dayak typology approach, the rhymes of the jonggan dance songs and the settlement patterns of Korek Village and forest tourism telling the meaning of the jungle for the Dayak community which is very valuable. important for their daily activities. Served as the basic design in forming zoning, circulation patterns, building orientation, and building form. The design of this project uses a qualitative method with case studies and Kengo Kuma's design methods. The results of the research are the design of the Kanayatn Dayak cultural ecotourism with the application of the aspect of beyond ecology, which can increase the involvement of local communities in optimizing the program of conservation of natural resources and culture.
\end{abstract}

Keywords: Culture; Dayak Kanayatn; ecology; forest; tour. 


\section{PENDAHULUAN}

Salah satu paru - paru dunia adalah Pulau Kalimantan dikarenakan luas hutannya. Selama ribuan tahun, orang Kalimantan hidup bersimbiosis dengan alam, dimana masyarakat lokal masih sanagt bergantung pada hutan dalam kehidupan tradisional mereka. Tingginya tingkat deforestasi hutan di Pulau Kalimantan, sering menjadi pusat perhatian nasional dan dunia karena tingkat perubahan hutannya yang sangat tinggi, karena pengalihan untuk penggunaan komersial, perternakan, pertanian, perkotaan dan berbagai kepentingan. Deforestasi hutan di Kalimantan dari tahun ke tahun semakin merajalela, dan jika deforestasi terus berkepanjangan sangat berdampak buruk bagi manusia dimasa yang akan datang dan memiliki dampak yang sangat buruk bagi tanah. Hilangnya tutupan hutan mengakibatkan penurunan yang signifikan dalam penyerapan karbon dioksida oleh tumbuhan hutan.

Pulau Kalimantan didominasi oleh suku dayak. Masyarakat dayak yang kehidupan tradisionalnya masih sangat bergantung pada hutan telah diusir dari tanah mereka atau dipaksa meninggalkan praktik dan mata pencahariannya. masyarakat lokal mengibaratkan hutan sebagai "pasar" yaitu sebagai sumber air bersih, tanaman obat, resin, kayu untuk rumah, perpian dan sampan, ikan dan tempat bermain. Sebagian hutan disungsikan seperti kebun suci yang tidak tersentuh untuk kegiatan ritual dan alasan spiritual. Masyarakat lokal membuka hutan dengan kearifan lokal yang diwarisi turun temurun dan tidak merusak alam, dalam berladang atau bersawah dan menorek karet.

Masyarakat Dayak memiliki persepsi holistik terhadap hutan, hutan bagi mereka tidak hanya bermakna ekonomis melainkan juga sosio budaya dan religious, dan juga bukan semata - mata berisi ragam tumbuhan dan hewan, melainkan mereka sendiri merupakan bagian yang tidak terpisahkan dari hutan, sehingga hutan yang ada dalam wilayah mereka mempunyai hak kedaulatan kepemilikan yang jelas dan terpastikan secara jelas sesuai hukum adat mereka

Salah satu wilayah yang mengalami perubahan tutupan hutan yang tinggi di Provinsi Kalimantan Barat adalah Kabupaten Kubu Raya (Ikhsani, 2019). Kabupaten Kubu Raya merupakan wilayah yang kaya akan lahan gambut, dan merupakan kawasan hutan mangrove terluas di Kalimantan. Perkembangan dan pembangunan wilayah ini menyebabkan pembukaan lahan gambut untuk berbagai penggunaan sehingga menyebabkan perubahan pola tutupan lahan (Iswati Sri dkk, 2013).

Rehabilitasi hutan hujan tropis menjadi salah satu upaya penanggulaan yang dapat dilakukan untuk mencegah kerusakan hutan hujan tropis di Kuburaya. Terdapat berbagai potensi daerah, yang memberikan beragam pengalaman menarik salah satunya sebuah destinasi wisata yang komplit, yaitu wisata kuliner, wisata budaya, terutama wisata alam nya. Udara yang segar, langit yang bertabur bintang, gesekan dedaunan dari rimba borneo, serta bunyi-bunyian alam yang membawa ketenangan menjadi suatu hal yang disebut sebagai pesona tropis Kalimantan barat.

Pemerintah kuburaya menerapkan skema transfer anggaran kabupaten berbasis ekologi (TAKE) untuk Alokasi Dana Desa (ADD), dimana anggaran tersebut untuk kegiatan berbasis kinerja lingkungan hidup dan kehutanan (eologis).

Diharapkan skema transfer anggaran kabupaten berbasis ekologi yang diterapkan oleh pemerintah kuburaya, mampu memperkuat ekowisata dan pemberdayaan usaha mikro, kecil, menengah didaerah setempat, sebab kuburaya mempunyai posisi strategis dan potensi pengembangan wisata. Terutama pada desa - desa yang tingkat perkembangannya masi tertinggal atau sangat tertinggal, sehingga desa tersebut dapat berkembang dan menjadi daya tarik dengan tetap memperhatikan pelestarian sumber daya alamnya. 
Dalam hal diperlukannya penyesuaian program ekowisata dan budaya yang dapat menyesuaikan dengan lingkungan dan menunjang aktivitas masyarakat lokal yang tinggal di Kecamatan Sungai Ambawang, sehingga analisis menggunakan metode desain milik Kengo Kuma dan pendekatan tipologi diusahakan dapat menjadi suatu jawaban dalam meningkatkan kualitas desain.

Penelitian ini bertujuan untuk mengurangi dampak negative pada alam dengan memberikan fungsi yang menyesuaikan dengan kebutuhan masyarakat, dengan program yang dapat mempromosikan wisata budaya lokal, dan hutan hujan tropis sebagai wadah untuk berinteraksi dan bersosialisasi, serta dapat memberikan pengetahuan terhadap pentingnya peran manusia dalam melestarikan alam dan lingkungannya, dengan harapan proyek yang dapat diterima masyarakat dan dapat menyenangkan bagi masyarakat sekitar.

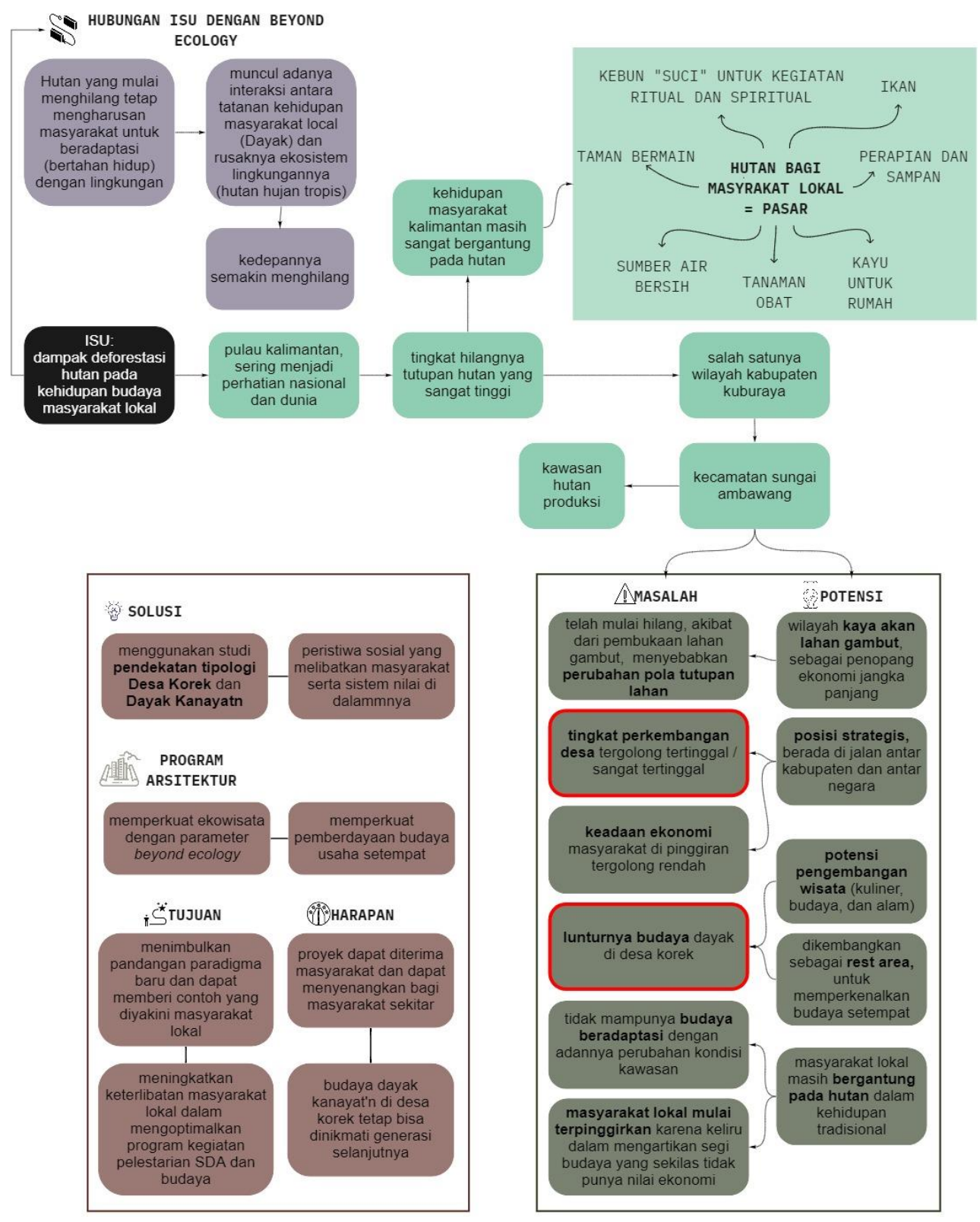

Gambar 1. Kerangka Berpikir

Sumber: Penulis, 2021 


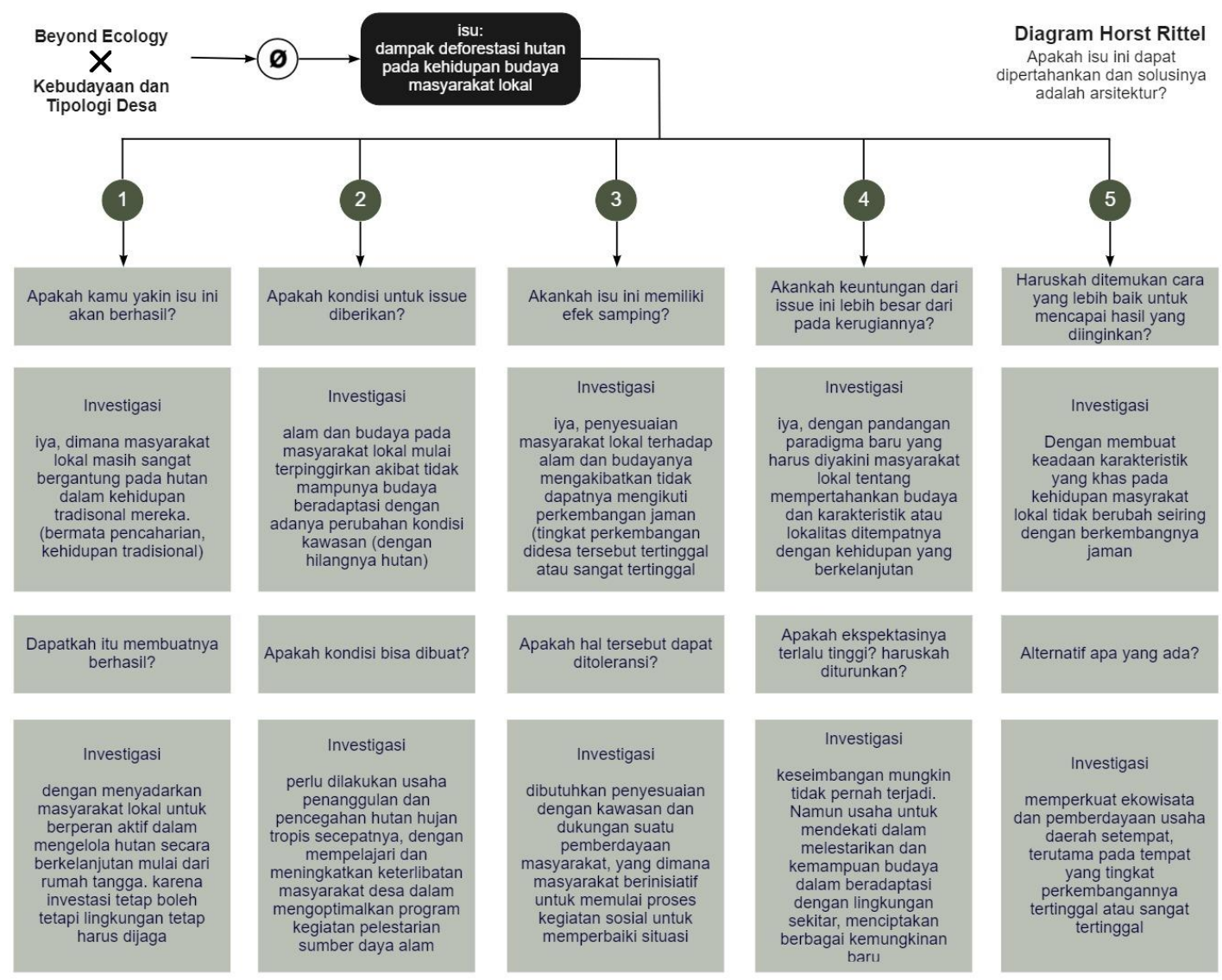

Gambar 2. Diagram Horst Rittel

Sumber: Penulis, 2021

\section{KAJIAN LITERATUR}

\section{Beyond Ecology}

Beyond ecology menjadi tema dalam desain proyek ini yang terdiri dari kata "Beyond" berasal dari bahasa inggris yaitu melampaui. Sedangkan "ekologi" berasal dari bahasa yunani, yaitu oikos dan logos. Oikos artinya rumah atau tempat tinggal, sedangkan logos artinya ilmu atau pengetahuan. ekologi yaitu ilmu yang mempelajari hubungan timbal balik antara makhluk hidup dan kondisi alam sekitar lingkungannya (Warno dkk, 2014). Beyond ecology adalah suatu kondisi ekosistem dengan kondisi formasi sosialnya yang mengalami percepatan (pemadatan waktu) dan kecepatan (jantung dunian keseharian) (Agustinus, 2021).

Parameter dalam Arsitektur menuju Beyond Ecology (Agustinus, 2021):

- Energy dan Emission adalah kemampuan dalam menerapkan zero $\mathrm{CO} 2$ emission dan meminimalisir efek dalam material dan konstruksi pada bangunan.

- Adaptation adalah kemampuan untuk melakukan riset dan desain yang berkaitan dengan dampak, misalnya: naiknya suhu bumi, kekeringan, banjir, perubahan populasi, dll.

- Resilience adalah adalah kemampuan untuk kelanjutan 'hunian' dan pemulihan cepat setelah kejadian guncangan, bencana alam, gangguan listrik atau iklim

- Sustainable digital adalah kemampuan untuk melihat data-data lingkungan sebagai Big Data dalam menentukan taktik dan strategi dalam membangun kualitas

- New technology adalah kemampuan memanfaatkan teknologi terbaru untuk meningkatan kualitas dan terapan ruang - kontruksi dan program bangunan.

- Context adalah kemampuan dalam melihat tempat dalam hubungan dengan lingkungan (flora - fauna, biotic - abiotic) dimana sebuah konfigurasi keruangan akan ditempatkan 


\section{Arsitektur Ekologi}

Prinsip-prinsip arsitektur ekologis, yaitu merespon iklim setempat, meminimalkan penggunaan energi, memanfaatkan material lokal, menyediakan sumber energi, air, pembuangan limbah, serta penggunaan teknologi tepat guna yang manusiawi (Frick, 2007). Arsitektur ekologis mempunyai unsur-unsur pokok (bumi, air, api, dan angin) yang dapat menghubungkan bangunan dan lingkungannya. Prinsip desain ekologi nya yaitu memenuhi solution grows from place (pemahaman atas masyarakat lokal, terutama aspek sosial-budaya), design with nature (desain yang direncanakan mampu menjaga ekosistem yang ada di dalamnya), meminimalisir pemakaian energi dan material, mengharmoniskan hubungan antara budaya dan alam, menjaga aspek-aspek lingkungan seperti tanah, tumbuh-tumbuhan, dan lain sebagainya.

Penerapan aspek ekologi dalam kondisi perancangan yaitu dengan adanya: Aspek struktur dan konstruksi, aspek bahan bangunan, aspek sumber-sumber energi dan pemanfaatannya bagi kehidupan sehari-hari, aspek manajemen limbah (utilitas), aspek ruang, meliputi zonasi, tata ruang, dan fungsinya, pemahaman terhadap sosial budaya masyarakat (understanding people), pemahaman terhadap kondisi setempat (understanding place), kesinambungan dengan alam (connecting with nature), pemberdayaan masyarakat sekitar (embracing co-creative design processes).

\section{Lokalitas}

Lokalitas adalah sebuah Gerakan yang memperjuangkan identitas kelokalan ditengah arus globalisasi. Kearifan lokal adalah warisan nenek moyang yang menyatu dengan nilai kehidupan dalam bentuk religi, budaya dan adat istiadat. Kearifan tradisional bersifat lokal sesuai dengan daerahnya masing-masing merupakan salah satu warisan budaya yang ada pada masyarakat lokal dan dilaksanakan secara turun temurun dilaksanakan suatu kelompok masyarakat lokal. Keberadaan kearifan lokal tradisional dari sisi lingkungan hidup sangat menguntungkan, karena secara langsung ataupun tidak langsung memelihara lingkungan serta mencegah terjadinya kerusakan lingkungan.

Budaya lokal sebagai sumber daya memrpesentasikan nilai-nilai budaya berbasis kearifan lokal pada masyarakat yang berasal dari masyarakat setempat (indigineous people) dan bersifat lokal (kedaerahan). Budaya lokal perlu memperkuat daya tahannya dalam menghadapi globalisasi budaya asing. Masyarakat lokal hidup berdampingan dengan alam, mereka memiliki pengetahuan yang diwariskan turun temurun tanpa merusak alam untuk memenuhi kebutuhan hidup.

\section{Ekowisata dan Budaya}

"Kami percaya bahwa masa depan pariwisata didasarkan pada hubungan manusia dengan alam. Arsitektur yang terintegrasi dengan baik dan berkelanjutan dapat memperkuat hubungan ini, tidak ada lagi yang dibutuhkan. " - Arsitektur Peter Pichler

Ekowisata adalah suatu bentuk wisata yang dikelola dengan pendekatan konservasi. Ekowisata pengelolaan alam dan budaya masyarakat berfungsi menjamin kelestarian dan kesejahteraan, sementara konservasi adalah upaya menjaga kelangsungan pemanfaatan sumber daya alam untuk saat ini dan yang akan datang (Lombok Pesona Sumbawa, 2015). Ekowisata diartikan sebagai perjalanan seorang turis ke daerah terpencil bertujuan menikmati dan mempelajari mengenai alam, sejarah dan budaya di suatu daerah, di mana pola ekowisatanya meningkatkan pendapatan ekonomi masyarakat lokal dan meminimalkan dampak negative terhadap lingkungan dan budaya setempat, dengan mendukung pelestarian alam (Affandi, 2017). 
Menurut Low Choy dan Heillbronn (1996), merumuskan lima faktor batasan yang mendasar dalam penentuan prinsip utama ekowisata, yaitu: 1) Lingkungan; ecotourism bertumpu pada lingkungan alam, budaya yang relative belum tercemar atau terganggu; 2) Masyarakat; ekotourism harus memberikan manfaat ekologi, sosial dan ekonomi langsung kepada masyarakat; 3) Pendidikan dan Pengalaman; Ekotourism harus dapat meningkatkan pemahaman akan lingkungan alam dan budaya dengan adanya pengalaman yang dimiliki; 4) Berkelanjutan; Ekotourism dapat memberikan sumbangan positip bagi keberlanjutan ekologi lingkungan baik jangka pendek maupun jangka panjang; 5) Manajemen; ekotourism harus dikelola secara baik dan menjamin sustainability lingkungan alam, budaya yang bertujuan untuk peningkatan kesejahteraan sekarang maupun generasai mendatang (Susilawati, 2016).

\section{Tipologi Desa}

Peraturan Menteri Dalam negeri Nomor 12 Tahun 2007 tentang Pedoman Penyusunan dan Pendaya gunaan Data Profil Desa dan Kelurahan mendefinisikan Tipologi Desa atau Kelurahan adalah kondisi spesifik keunggulan sumber daya alam, sumber daya manusia dan potensi kelembagaan serta potensi sarana prasarana dalam menentukan arah pengembangan dan pembinaan masyarakat berdasarkan karakteristik keunggulan komparatif dan kompetitif dari setiap desa dan kelurahan (Suparmini dan Wijayanti, 2015).

Tipologi desa merupakan fakta, karakteristik dan kondisi nyata yang khas, keadaan terkini didesa, maupun keadaan yang berubah, berkembang dan diharapkan terjadi dimasa depan (visi desa) (Database Peraturan JDIH BPK RI, 2016). Tipologi wilayah perdesaan adalah suatu upaya mengelompokkan desa berdasarkan kesamaan ciri-ciri wilayah dan masyarakatnya, tipologi desa juga merupakan teknik, cara mengenal desa sehingga konkrit permasalahannya (Suparmini dan Wijayanti, 2015).

Pengelompokkan tipologi desa dapat diuraikan sekurang-kurangnya didasarkan atas hal-hal sebagai berikut (Database Peraturan JDIH BPK RI, 2016):

a. Berdasarkan kekerabatan

Dikenal desa geneologis, desa terirorial dan desa campuran

b. Berdasarkan hamparan

Dapat dibedakan desa pesisir/desa pantai, desa dataran rendah/ lembah, desa dataran tinggi, dan desa perbukitan/pegunungan

c. Berdasarkan pola pemukiman

Dikenal desa dengan permukiman menyebar, melingkar, mengumpul, memanjang (seperti pada bantaran sungai/jalan)

d. Berdasarkan pola mata pencaharian / kegiatan utama masyarakat

Dapat dibedakann desa pertanian, desa nelayan, desa industri (skala kerajinan dan atau manufaktur dengan teknologi sederhana dan madya, serta desa perdagangan (jasa)

e. Berdasarkan tingkat perkembangan kemajuan desa

Dapat dikategorikan desa tertinggal / sangat tertinggal, desa berkembang, serta desa maju / mandiri. Kategorisasi ini dilakukan dengan pendekatan ilmiah yang didukung data statistic sehingga didapatkan peringkat kategoris kemandirian / kemajuan desa.

Dengan demikian setiap desa pasti memiliki karakteristik yang dapat didefinisikan secara bervariasi dari kombinasi karakteristik / tipologi. Artinya, desa memiliki tipologi yang berbedabeda atau beragam, dari desa satu dengan desa lainnya (Database Peraturan JDIH BPK RI, 2016). Horst Rittel

Menurut Horst Rittel, rasa objektivitas dalam menangani masalah harus dilihat sebagai sarana "pertukaran informasi di antara mereka yang berkepentingan untuk mencapai saling pengertian." Dapat dilihat bahwa mendesain sebagai pembangkit ide dan pemahaman. 
Sehingga, menghubungkan objektivitas dapat dikaitkan dengan proses mengumpulkan informasi untuk menghasilkan pengetahuan faktual pembelajaran. Misalnya, jam tangan dirancang dan diproduksi melalui serangkaian proses di mana desainer terus-menerus mengajukan pertanyaan dan berdebat dengan dirinya sendiri dan orang lain atas keuntungan dan kerugian dari "solusi" alternatif.

Horst Rittel memperkenalkan beberapa ide dasar tentang analisis dalam mendesain (Rith, Chanpory and Hugh Dubberly, 2006):

- Masalah sederhana (masalah yang sudah didefinisikan) mudah dipecahkan, karena mengartikan masalah secara inheren mendefinisikan solusi.

- Definisi masalah bersifat subjektif datang dari sudut pandang.

- Beberapa masalah yang tidak dapat diselesaikan disebut masalah jahat, tetapi kadang kadang dapat diselesaikan.

- Memecahkan masalah sederhana dapat mengarah pada peningkatan, tetapi bukan inovasi. Untuk inovasi, kita perlu membingkai ulang masalah jahat.

- Karena satu orang tidak mungkin mengingat atau melacak semua variabel (dari keadaan yang ada dan yang diinginkan) dalam masalah, menjinakkan masalah jahat membutuhkan banyak orang, dan semua harus menyepakati tujuan dan tindakan untuk mencapainya. Ini membutuhkan pengetahuan tentang tindakan, bukan hanya fakta.

- Sains berkaitan dengan pengetahuan faktual (apa adanya), desain berkaitan dengan pengetahuan instrumental (bagaimana apa yang berhubungan dengan apa yang seharusnya), bagaimana tindakan dapat memenuhi tujuan.

- Proses argumentasi dalam mendesain merupakan kunci dan satu-satunya metode untuk menjinakkan masalah -masalah.

- Proses ini bersifat politis.

Diagram Horst Rittel tetap penting bagi para desainer karena dua alasan. Pertama, ia mengartikulasikan hubungan antara sains dan desain, khususnya batasan proses desain berdasarkan pandangan rasional sains abad ke-19. (Namun demikian, pandangan rasionalis "pemecahan masalah" desain tetap menjadi kepercayaan populer yang dipegang secara luas.) Kedua, ia mengusulkan prinsip-prinsip untuk menangani keterbatasan ini (Rith, Chanpory and Hugh Dubberly, 2006).

\section{METODE}

\section{Metode Pengumpulan Data}

Metode penelitian yang digunakan adalah kualitatif, dengan menggunakan metode studi kasus (case study). Pengumpulan data, melalui studi literatur dan studi kasus yang relevan dengan isu yang terpilih. Setiap data yang diperoleh untuk meningkatkan pemahaman penulis dalam penyelesaian masalah dan mendukung proses perancangan.

\section{Metode Desain Milik Kengo Kuma}

Metode desain yang diterapkan pada proyek "Forest Tour in Dayak Kanayatn Village" adalah metode desain milik kengo kuma. Dalam proses desainnya, kengo kuma memiliki 4 faktor dalam mengelolah desain Arsitekturnya yaitu:

- Historis

Pendekatan historis dengan melestarikan budaya tradisional, ia dapat membuat suatu keajaiban dalam karyanya, menciptakan suatu karya yang ikonik.

- Relationship With Nature

Dalam berkarya Kengo Kuma sebisa mungkin tidak menebang pohon atau tumbuhan, yang ada di sekeliling lahan, dimana bangunan akan dibangun. "Don't cut the landscape! Cut the landscape means cut the beauty," 
- Be friends with the surroundings

Arsitek ini selalu memperhatikan lingkungan sekitar lahan pembangunan. Mulai dari sejarah, iklim, bangunan-bangunan asli atau bangunan lama, dan sebagainya. Menurutnya, lingkungan sekitar akan sangat mempengaruhi desain yang dibuatnya. Karya yang luar biasa indah, menurutnya, tidak ada gunanya jika tidak "berteman" dengan lingkungan sekitar. Karya arsitektur yang baik, adalah yang bisa menyatu dengan alam sekitar.

- Material

Kengo Kuma selalu menggunakan material lokal selokal-lokalnya, bahkan kalau bisa sama sekali tidak menggunakan sarana transportasi atau pengiriman apapun.

\section{Metode Pendekatan Tipologi}

Mempelajari karakteristik dan kondisi budaya dayak kanayatn, dan interaksi manusia dengan alam hutan, flora, fauna \& sungai. agasan 'tipe' sebagai model, yang diwakili grafis sebagai sumbu struktural, Durand, memperkenalkan ajaran yang fundamental untuk bekerja secara tipologis, preseden, klasifikasi, taksonomi, kontinuitas, pengulangan, diferensiasi dan reinvention. Ambisinya adalah untuk sistematisasi pengetahuan arsitektur teoritis dan untuk menetapkan metode rasional untuk merancang bangunan.

Desain proyek ini menggunakan pendekatan tipologi Dayak kanayatn dan desa korek dari pola pemukiman yang dulunya berada didekat aliran sungai dan skrg mengikuti pola jalan dan pola masyrakatny yang membentuk adanya ruang communal space, menggunakan ornamen Dayak kanayatn dan material alami, komponen bangunan dari rumah betang bagi orangg Dayak kanayatn sebagai jantung struktur sosial kehidupan mereka.

\section{DISKUSI DAN HASIL}

\section{Tapak Perancangan}

Lokasi : Jalan Trans Kalimantan Desa Korek, Kecamatan Sungai Ambawang Luas Tapak : $17.310 \mathrm{M}^{2}$

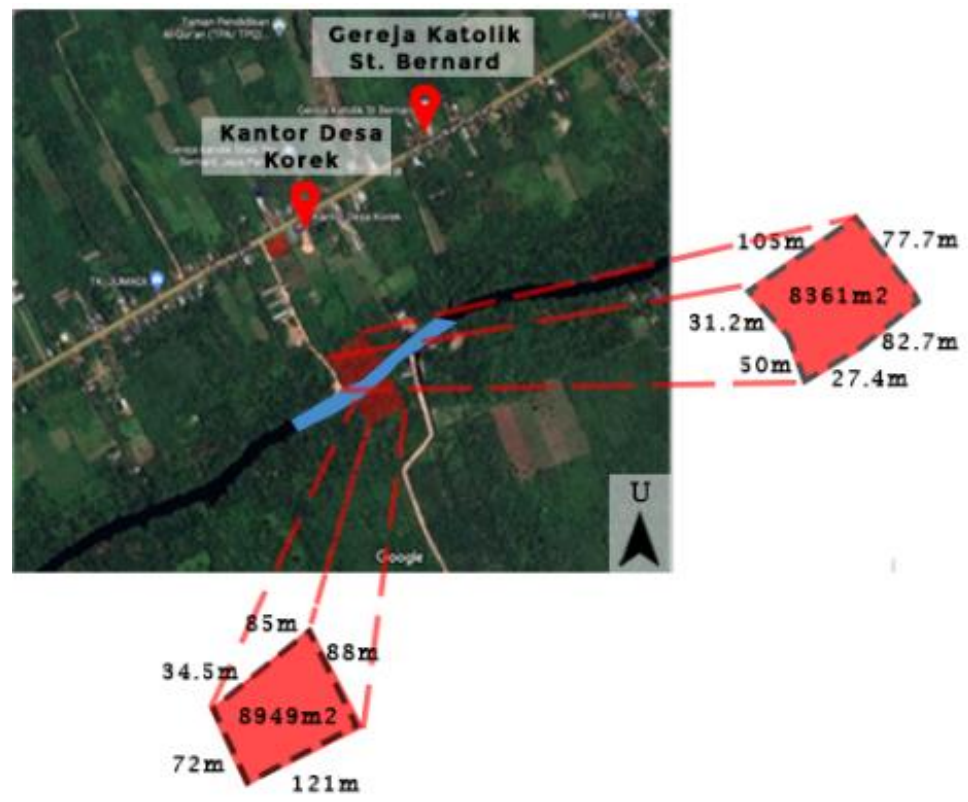

Gambar 3. Luas Tapak Dan Letak Tapak Sumber: Penulis, 2021 


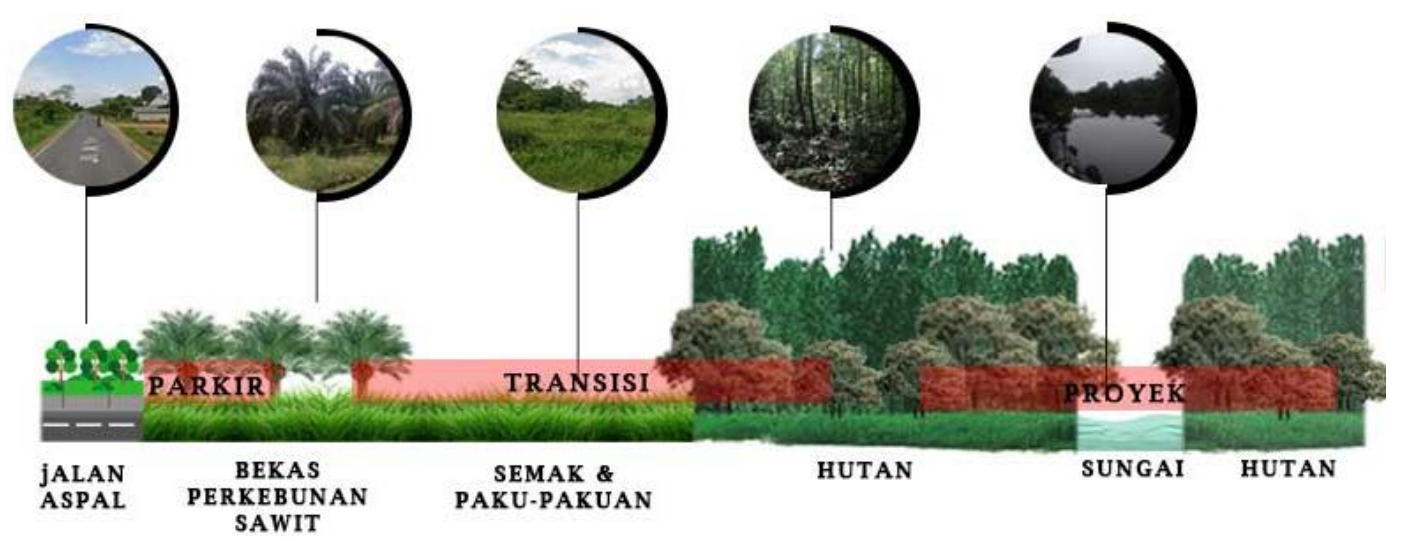

Gambar 4. Lokasi Tapak

Sumber: Penulis, 2021

Gambaran Umum Lokasi, pengembangan wilayah di Kecamatan Sungai Ambawang, Kabupaten Kuburaya masih belum optimal didaya gunakan. Lokasi tapak dilalui oleh jalan lintas Kalimantan sangat strategis bila dihubungkan dengan pengembangan ekonomi dan budaya masyarakat karena menghubungkan antar kabupaten di Kalimantan Barat dan menjadi jalan penghubung dengan negara Malaysia (Sabaruddin, 2012).

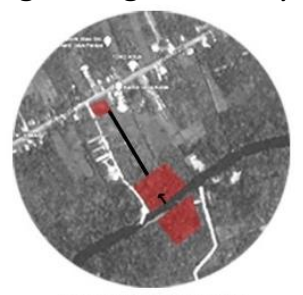

AKSESIBILITAS

Pembuatan akses tambahan untuk entrance pejalan kaki dari tempat parkir menuju tapak $\pm 200 \mathrm{~m}$, dan terdapat akses entrance dari sungai menggunakan perahu

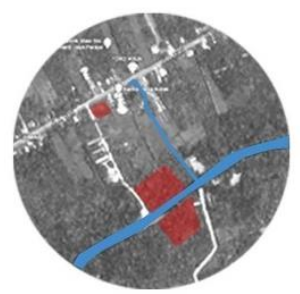

RIVER FLOW

Sungai berada ditengah tapak, sehingga dapat mengingatkan kearifan lokal masyarakat dayak untuk tetap menjaga dan melestarikan alamnya

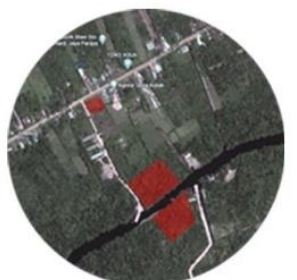

GREEN SPACE

Area bekas deforestasi yang Berada di area pemukiman

sudah lama tidak digunakan penduduk dan kantor desa \& dikelilingi area hijau, yang membuat area sekitar tapak menjadi lebih asri yang sekaligus dapat membantu mengoptimalkan program ekowisata budaya

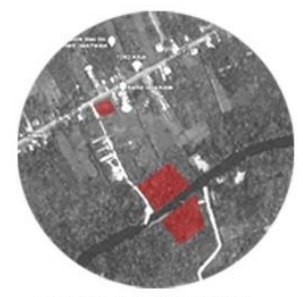

POLA TANAMAN

pohon yang besar dan tinggi pada tapak, digunakan sebagai pola yang membentuk sirkulasi dan orientasi bangunan

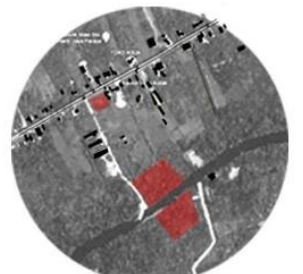
korek, yang dimana masyarakat lokal melakukan kegiatan di kantor desa korek sehingga masyarakat dapat ikut terlibat dalam mengoptimalkan program kegiatan pelestarian SDA dan budaya

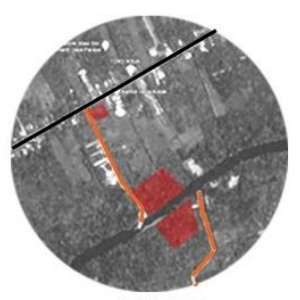

STREET

Berada di posisi strategis yaitu, jalan Trans Kalimantan yang merupakan jalan penghubung antar kabupaten dan negara, serta didominasi oleh

masyarakat dayak ditepi jalan Trans Kalimantan

Gambar 5. Analisis Tapak

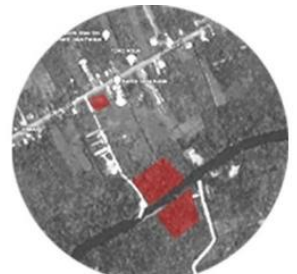

VIEW \& ORIENTASI Bangunan berorientasi ke dalam yang digunakan

sebagai pusat/poros

bangunan dengan mengangkat potensial lokalitas, sungai dan hutan. bangunan mempertimbangkan view ke dalam dan luar banguan

Sumber: Penulis, 2021 


\section{Tipologi Desa Korek}
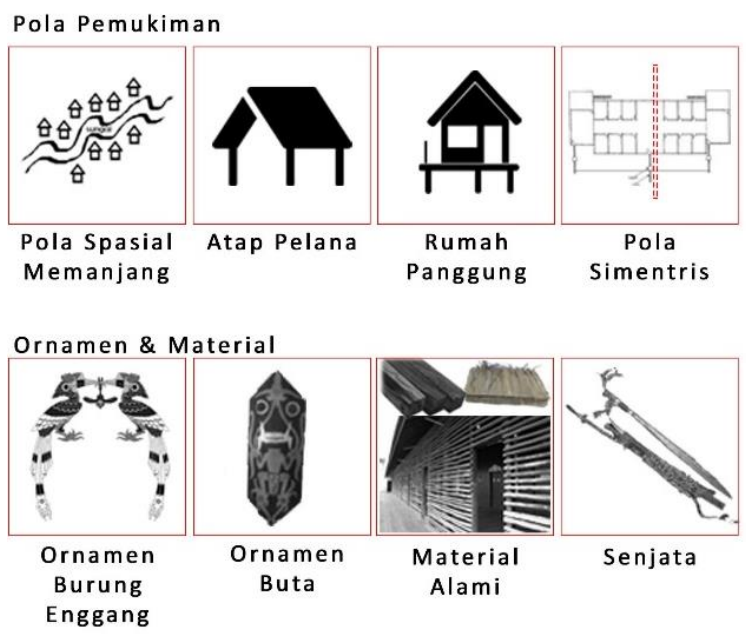

Motif Hias
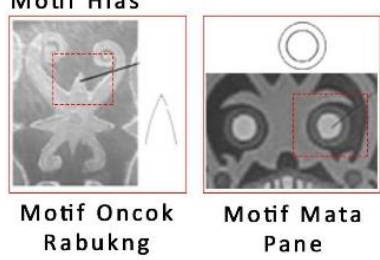

Motif Mata
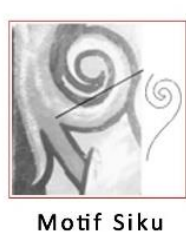

Kaluakng

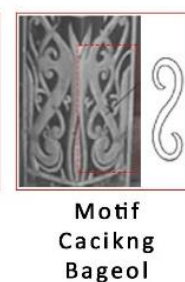

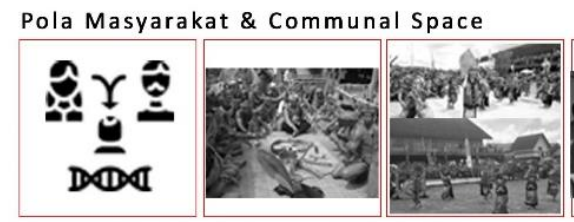

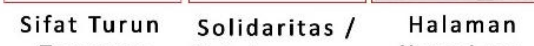

Temurun Kekeluargaan Yang Luas

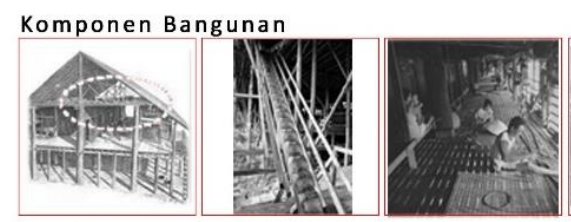

Kolom

Tangga Berjumlah

Pante / Ganjil

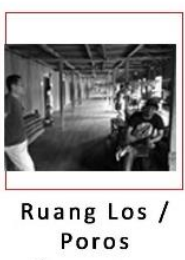

Bangunan

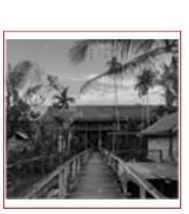

Jembatan

Gambar 6. Diagram Tipologi Dayak Kanayatn Desa Korek

Sumber: Penulis, 2021

Secara umum pola domisili penduduk Kabupaten Kubu Raya bertipe konsentris dan terpusat pada jalur utama transportasi. Kondisi ini dikarenakan pada lokasi tersebut, umumnya dekat dengan pusat pembangunan dan memiliki dukungan fasilitas, sarana dan prasarana, infrastruktur dan suprastruktur yang memadai. Pada daerah yang jauh dari pusat kegiatan, umumnya fasilitas publik masih terbatas. (Nunik dkk, 2016).

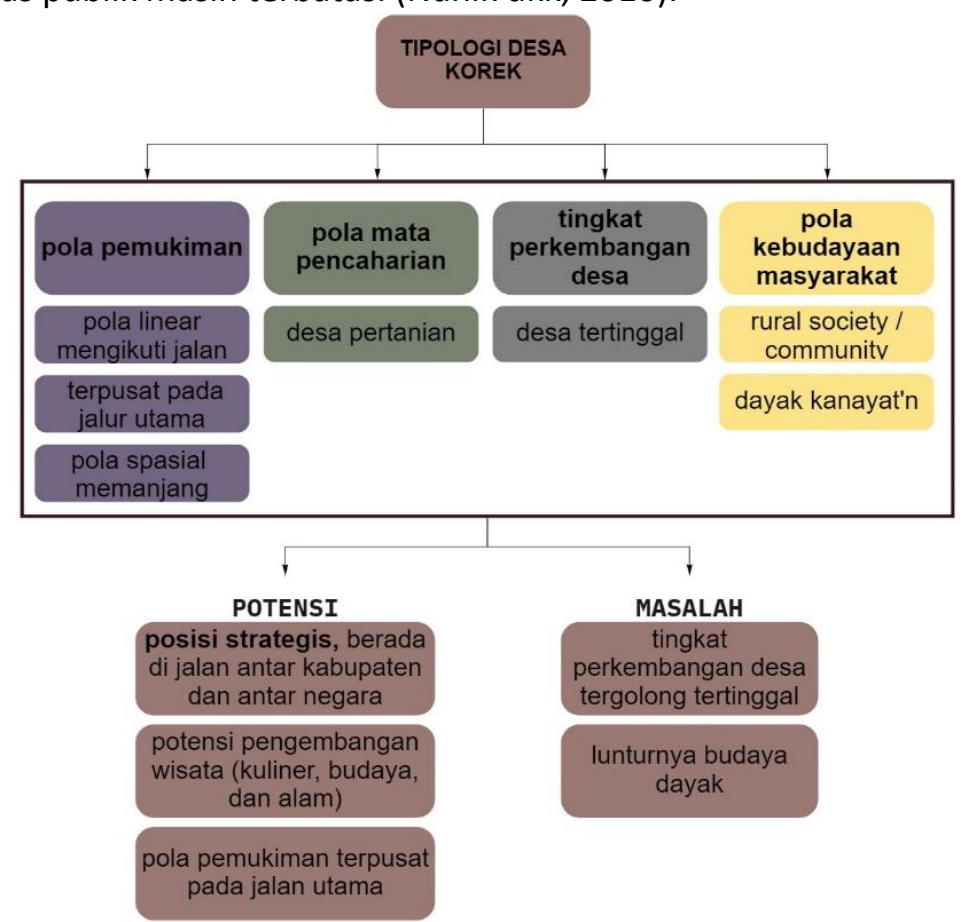

Gambar 7. Diagram Tipologi Desa Korek Sumber: Penulis, 2021 


\section{Konsep Bangunan}

Hutan merupakan suatu unsur yang sangat penting dalam kehidupan sosial masyarakat Dayak. Mereka memiliki persepsi holistik terhadap hutan, bagi mereka hutan tidak hanya bermakna ekonomis melainkan juga sosio budaya dan religious, serta bukan semata-mata berisi ragam tumbuhan dan hewan, melainkan mereka sendiri merupakan bagian yang tidak terpisahkan dari hutan.
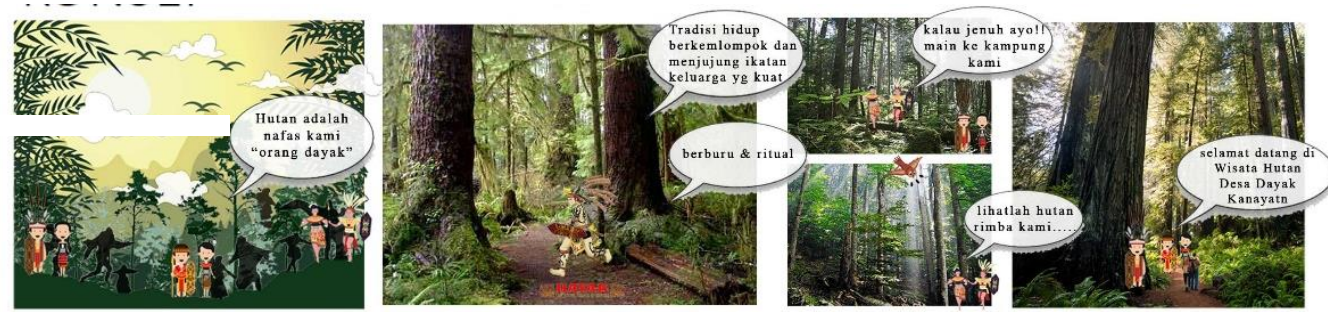

Gambar 8. Suasana Hutan Masyarakat Dayak

Sumber: Penulis, 2021

Konsep wisata di ambil dari fungsi hutan bagi masyarakat sendiri yang diibaratkan sebagai tempat berteduh dan taman bermain dikala masyarakat merasa jenuh bekerja dan jenuh dirumah. Sehingga forest tour mengisahkan makna hutan rimba bagi masyarakat Dayak Kanayatn, yang bernilai sangat penting bagi kehidupan aktivitas sehari - hari mereka. Berawal dari menggoreskan garis pada secarik kertas mengikuti pola tanaman pada tapak sebagai dasar menggambar yang membentuk sirkulasi.

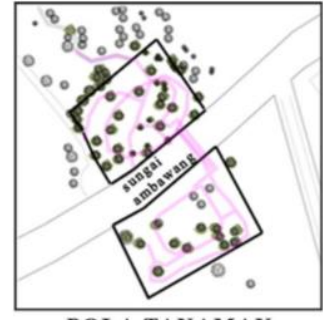

POLA TANAMAN

tanaman besar pada tapak digunakan sebagai pola untuk membentuk sirkulasi pejalan kaki

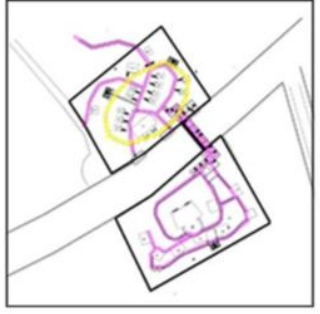

SIRKULASI JALAN \& BANGUNAN

bangunan berorientasi ke sirkulasi pejalan kaki yang dibagi menjadi 2 sirkulasi

Gambar 9. Konsep Tapak

Sumber: Penulis, 2021

Masyarakat dayak merupakan masyarakat yang komunal dan hidup menyatu dengan tujuan hidup komunal 1 kesatuan. Tradisi hidup berkelompok dan menjunjung ikatan keluarga yang kuat, membuat masyarakat tradisional dayak menggunakan konsep rumah panjang / rumah betang sebagai hunian Bersama, yang merupakan jantung struktur sosial kehidupan orang Dayak.

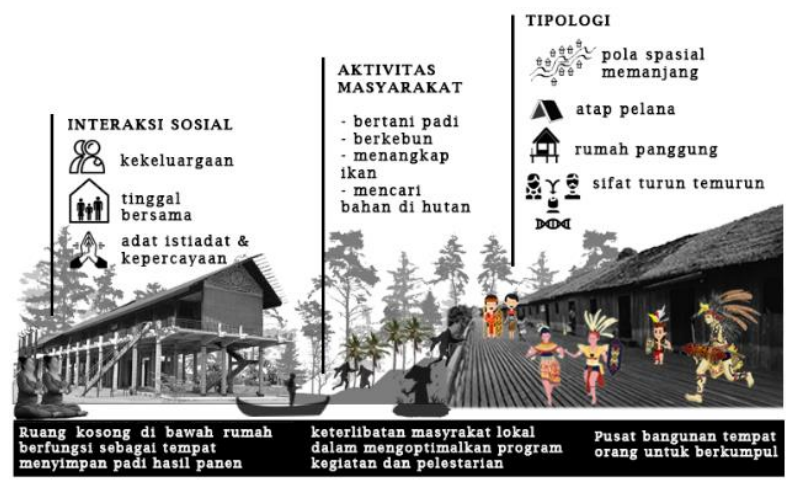

Gambar 10. Data Spesifik Rumah Panjang Sumber: Penulis, 2021 


\section{Zonasi Tapak}

Penentuan zoning tapak, menggunakan Teori Durkeim mengenai "The Division of Labour and Society" mengenai solidaritas sosial. Menurut Durkeim solidaritas sosial dibagi menjasi 2 yaitu: solidaritas organisasi dalam masyarakat maju pada tapak wisata dan rest area, sedangkan solidaritas mekanis dalam masyarakat tradisional pada tapak ritual dan hunian. Bagian khas rumah panjang yang diterapkan dalam desain proyek ini adalah setiap massa bangunan digunakan sebagai ruang tempat berkumpul, musyarawah, bermain, dll. Pada bagian tengah kawasan digunakan sebagai poros bangunan tempat masyarakat berkumpul. Letak toilet yang posisinya berada di belakang massa dan letaknya terpisah dengan bangunan utama mengikuti tipologi rumah panjang dayak kanayatn berfungsi untuk menimbulkan kualitas kehidupan masyarakat Dayak.

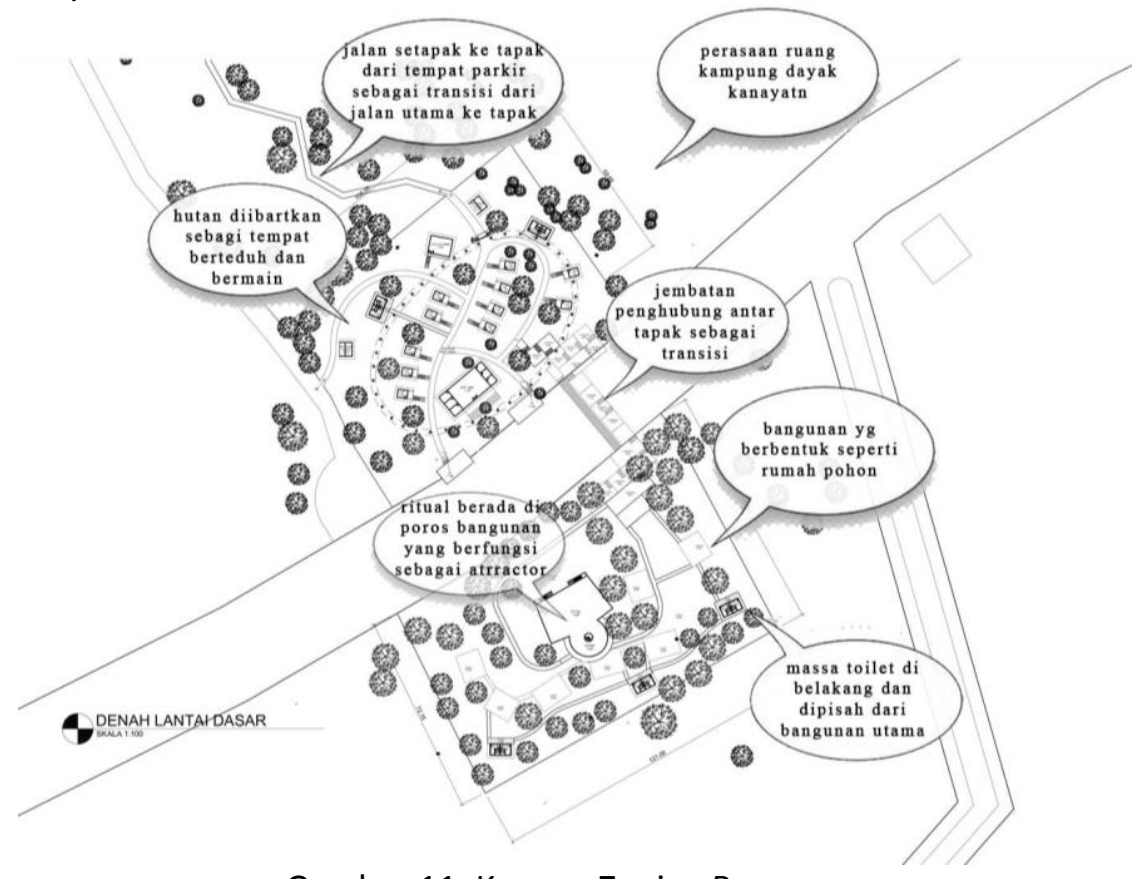

Gambar 11. Konsep Zoning Bangunan

Sumber: Penulis, 2021

Menggunakan material alami dari tipologi rumah Panjang yang menggunakan material langsung dari alam dan tidak bercampur dengan zat kimia, buktinya

- Bagian pondasi menggunakan kayu yang langsung menancap ke tanah

- Kolom struktur menggunakan kayu belian

- Lantai papan kayu rapat di dalam bangunan, dan lantai papan kayu berjarak untuk di teras bangunan

- Bagian dinding, menggunakan papan kayu dan kulit kayu

- Menggunakan atap rumbia / nipah

- Masyarakat menggunakan sistem pondasi tradisional yang dinamakan pondasi tiang tongkat untuk menopang beban konstruksi

Material bangunan mengkamuflase dari warna alam, sehingga bangunan dapat menyamar dengan lingkungan sekitar dan mereka dapat merasa bangunan dan ruang didalamnya merupakan bagian dari alam.

\section{Bentuk Bangunan}

Pada massa ritual, menara pantau berbentuk seperti patahan batang pohon, yang meruncing ke atas dimana berfungsi sebagai media komunikasi ke alam roh nenek moyang, dan berfungsi 
untuk melihat situasi dan kondisi. Pada bentuk massa wisata berfungsi untuk solidaritas, dengan menggunakan bagian - bagian pohon (daun, badan dan akar pohon). Pada massa bangunan hunian, wisata dan rest area menggunakan bagian dari rumah betang, yaitu bagian atap, bangunan utama, dan struktur panggung.

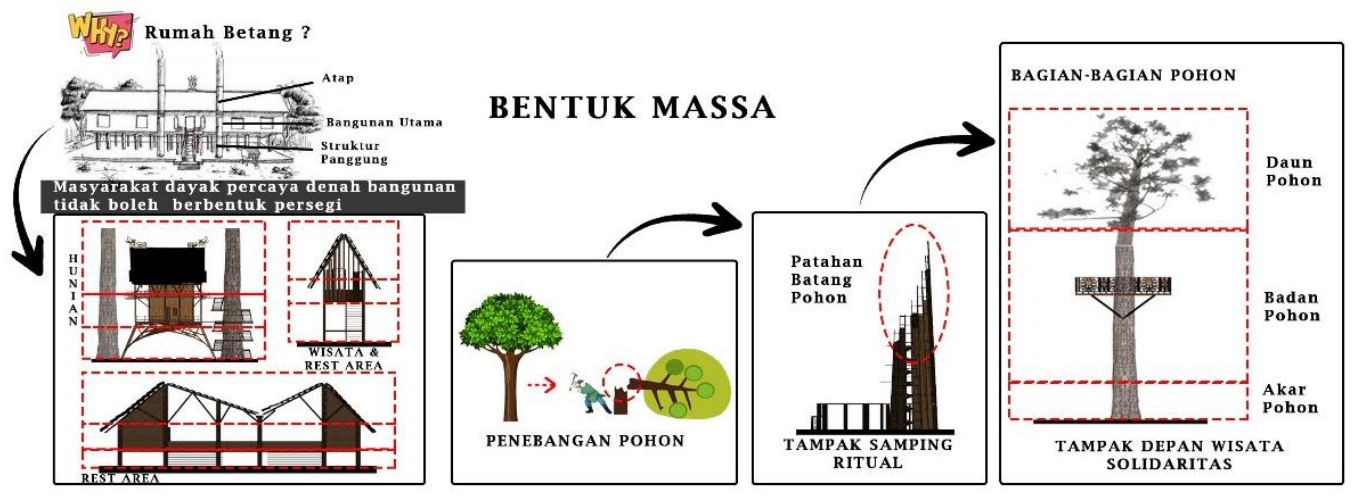

Gambar 12. Asal Mula Bentuk Massa

Sumber: Penulis, 2021

Tapak wisata dan rest area, berfungsi untuk mengenang kembali suasana kualitas kehidupan sehari hari perkampungan dayak kanayatn dimasa lampau, sehingga generasi penerus dapat melihat peninggalan atau warisan budaya dari leluhurnya. Program bangunan berkaitan dengan masyarakat Dayak yang mengibaratkan hutan sebagai tempat bermain dan berteduh, sembari mendengar kicauan burung dan suara air.

Tapak ritual dan hunian, berfungsi sebagai pusat aktivitas budaya dan kehidupan spiritual serta segala proses kehidupan yang berjalan dari waktu ke waktu, serta pada tapak ini ingin memunculkan suasana budaya lokal yang mempresentasikan nilai-nilai budaya yang berasal dari masyarakat setempat, sehingga keberadaan identitas lokal masyarakat tetap ada dan terjaga. Tradisi hidup berkelompok dan menjunjung ikatan keluarga yang kuat dijadikan sebagai desain dasar untuk hunian Bersama. Hunian-hunian tunggal yang saling menyambung menjadi 1 kesatuan diibaratkan dengan lebar sayap burung enggang, yaitu sebagai tempat perlindungan bagi rakyatnya yang membentang luas, seluas angkasa dengan menggunakan tipologi masyarakat yang komunal dan hidup menyatu. Ornament burung enggang diatap bangunan dianggap sebagai symbol pemimpin idaman yang mencintai perdamaian.

\section{Beyond Ecology}

Menggunakan parameter Beyond Ecology dalam Arsitektur:

- Energy and Emission memanilisir efek karbon dalam penggunaan material alami (kayu, batu, kulit pohon, daun rumbia) dan struktur panggung dalam pengoperasian bangunan.

- Adaptation

kemampuan masyarakat lokal terhadap alam dan budayanya untuk beradaptasi mengikuti perkembangan jaman, dalam meminimalisir kepunahan budaya Dayak Kanayatn di Desa Korek

- Resilience

penerapan struktur panggung dan material yang tahan cuaca, dikarenakan tipologi pemukiman mereka dulunya didirikan di pinggir sungai dan untuk mengantisipasi banjir, serta tipologi tanah yang gambut.

- Context

membuat ekowisata budaya yang menyatukan kegiatan social budaya serta religi dengan ekosistem alam. Menghadirkan pengalaman meruang yang bebas pada hunian dan 
ekowisata dimana solidaritas social yang menjadi kunci utama / ciri khas budaya setempat.

\section{- New Technology}

kualitas dan terapan keruangan yang dihasilkan dari tipologi Desa Korek dan rumah betang suku Dayak Kanayatn, kedalam bentuk yang lebih menyesuaikan dengan kondisi alam dan program bangunan

\section{KESIMPULAN DAN SARAN Kesimpulan}

Proyek ini dimulai dengan mengangkat isu "hilangnya tutupan/ deforestasi hutan, yang berdampak pada kehidupan masyarakat lokal", di Kalimantan Barat. Lajunya perubahan tutupan hutan di Kabupaten Kuburaya yang mempengaruhi budaya didesa korek, yang dimana masyarakat Dayak kanayat'n masih bergantung pada hutan dalam kehidupan tradisional mereka, tapi alam dan budaya pada masyarakat lokal mulai terpinggirkan karena keliru dalam mengartikan segi budaya yang sekilas tidak punya nilai ekonomi, menyebabkan perhatian dan usaha pemeliharaan adat istiadat sosial budaya hilang. Kebutuhan ekonomi yang selalu menjadi factor penting dalam kehidupan, membuat orang tidak mengutamakan tradisi dalam melakukan segala kegiatan mereka. Pilihan untuk melupakan tradisi otomatis akan menghilangkan keberadaan dari tradisi itu sendiri

Dalam desain proyek Program Ekowisata dan Kebudayaan menggunakan metode desain kengo kuma yang melihat sejarah budaya tradisional di suatu kawasan, kemudian mendesain bangunan yang berhubungan dengan alam tanpa merubah bentuk tapak, menggunakan material lokal. Hilangnya tutupan hutan di kecamatan sungai ambawang bukan masalahnya, karena merupakan hutan produksi tetapi masalahnya adalah lunturnya budaya Dayak masyarakat desa korek. Studi tipologi desa korek digunakan sebagai bahan kajian dalam program keruangannya, yaitu pola pemukiman yang memanjang yang mengikuti jalan. Program aktivitas didalamnya berupa hasil dari aktivitas budaya Dayak kanayat'n dan potensi wisata yang dapat meningkatkan keterlibatan masyarakat desa dalam mengoptimalkan program kegiatan pelestarian SDA dan budaya.

Hubungan isu dengan beyond ecology adalah Hutan hujan tropis yang mulai menghilang tetap mengharuskan masyarakat untuk beradaptasi (bertahan hidup) dengan lingkungan, sehingga muncul adanya interaksi antara tatanan kehidupan masyarakat lokal (Dayak) dan rusaknya ekosistem lingkungannya (hutan hujan tropis) kedepannya yang semakin menghilang.

\section{Saran}

Diperlukannya studi lanjutan dalam proyek wisata hutan di desa Dayak kanayatn yang ada untuk dapat meningkatkan kualitas dari wisata hutan di desa korek, semua parameter nya bisa ditajamkan, dan lebih realistis.

\section{REFERENSI}

Affandi, L. (2017). Ecotourism. Diunduh 9 Maret 2021. Dari:https://leonardoaffandi.wordpress.com/2017/01/19/ecotourism/. (disarikan dari berbagai sumber).

Database Peraturan JDIH BPK RI. (2016). Peraturan Daerah (PERDA) tentang Rencana Tata Ruang Wilayah Kabupaten Kubu Raya Tahun 2016 - 2036. LD.2016/NO.7, TLD No.7, LL KAB. KUBU RAYA: 131 HLM

Hasriyanti, N, Andi Z. Z. and Ismail R. (2016). The Impact Of Land Use Change And The Factors Affecting The Settlement On The Ambawang Corridor. Tata loka - Volume $x x$ Number $y$-Month Year - p ISSN 0852-7458 - e ISSN 2356-0266. 
Ikhsani, Hanifah. (2019). Tipologi Perubahan Tutupan Hutan di kabupaten kuburaya Kalimantan Barat. Jurnal Kehutanan. Vol. 14 No. 1.

Iswati, S., Suntoro W. A. dan Sri B. (2013). KAJIAN Perubahan Pola Tutupan Lahan Gambut Terhadap Anomali Iklim di Wilayah Kabupaten Kuburaya Propinsi Kalimantan Barat. Jurnal Ekosains. Vol. V No. 2.

Lombok, Pesona Sumbawa. (2015). Pendekatan Pengelolaan Ekowisata. [Online]. Diunduh 18 Februari 2021. Dari: http://www.disbudpar.ntbprov.go.id/pendekatanpengelolaan- ekowisata/.

Rith, C. and Hugh D. (2006). Why Horst W.J. Rittel Matters. Design Issues, Volume 22, Number 4.

Sabaruddin, R. (2012). Potensi Pariwisata Kuburaya. [Online]. Diunduh 18 Februari 2021. Tersedia:https://bersamakitabisakr.wordpress.com/potensi-pariwisata-kubu-raya/.

Suparmini, Agustina T. W. (2015). Masyarakat Desa dan Kota (Tinjauan Geografis, Sosiologis, dan Historis). [Online]. Diunduh 19 Februari 2021. Dari:http://staffnew.uny.ac.id/upload/ 198608172014042001/pendidikan/bahan-ajar-masy- kota-desa.pdf.

Susilawati. (2016). Pengembangan Ekowisata Sebagai Salah Satu Upaya Pemberdayaan Sosial, Budaya dan Ekonomi Dimasyarakat. [Online]. Diunduh 9 Maret 2021. Dari:http://ejournal.upi.edu/index.php/gea/ article/download/1690/1141.

Warno, S U., Sutriyono, Reda R. (2014). Pengertian Ruang Lingkup Ekologi dan $\begin{array}{lllll}\text { Ekosistem. } & \text { [Online]. } & \text { Diunduh } & 18 & \text { Februari }\end{array}$ Dari:http://repository.ut.ac.id/4305/1/BIOL4215-M1.pdf. (disarikan dari berbagai sumber). 
